\title{
De la ley de la calle a la ley de las élites: la sociedad civil en la encrucijada de la gubernamentalidad en América Latina
}

Morgan Quero*

\begin{abstract}
In the society of risk, the acceleration and multiplication of political crises and the uncertainty produced by the effects of the democratic modernisation create hitherto unheard-of political gaps. Such gaps are successfully filled by actors of the civil society when it is necessary to take government responsibilities. Implicitly, it is possible to track authoritarian characteristics coming from the continuities of the Latin American political culture in which the elites appear with a renewed and predominant leadership role. In this way, the authoritarism, masqueraded as democratic, would not be originated in the deceptive theoretical separation of Estate and civil society, but in their enigmatic mutual understanding, in their battle to define governmentality. It is indeed a battle expressed in terms of over-representation of the elites and the gradual disappearance of the self-representation of the popular sectors.
\end{abstract}

Keywords: civil society, presidentialism, governmentality, crisis, democracy, elites, authoritarism.

\section{Resumen}

En la sociedad del riesgo, la aceleración y multiplicación de las crisis políticas y la incertidumbre producida por efectos de la modernización democrática genera vacíos políticos, que son ocupados por actores de la sociedad civil al asumir responsabilidades de gobierno. Pero se pueden rastrear rasgos autoritarios, reflejo de las continuidades de la cultura política latinoamericana, donde las élites reaparecen con un papel de liderazgo. Así el autoritarismo con rostro democrático se originaría, no tanto en la supuesta separación teórica entre Estado y sociedad civil, sino más bien en su compenetración, en su batalla por definir la gubernamentalidad, expresada a través de la sobre-representación de las élites y la paulatina desaparición de la auto-representación de los sectores populares.

Palabras clave: sociedad civil, presidencialismo, gubernamentalidad, crisis, democracia, élites, autoritarismo.

* Centro Regional de Investigaciones Multidisciplinarias, Universidad Nacional Autónoma de México. Correo-e: morgan@servidor.unam.mx. 


\section{Introducción}

Si en los años 80 América Latina vivió fenómenos concomitantes y paradójicos como la transición a la democracia, la década perdida y la descentralización del Estado, en los 90 el panorama fue todavía más complejo y contradictorio: fortalecimiento de la sociedad civil y neoliberalismo globalizador con inestabilidad institucional. En su conjunto, estos fenómenos terminaron por degradar al conjunto de las democracias, restándole legitimidad y confianza a instituciones y actores que tenían por tarea consolidar los frágiles sistemas políticos.

Con la caída del muro de Berlín y el consecuente mal llamado fin de las ideologías, las opciones revolucionarias de izquierda se diluyeron y la 'utopía' se desarmó. A pesar de que se mantienen focos guerrilleros de incierta claridad ideológica y en franca descomposición en países como Colombia, Perú, México, Bolivia; y a pesar de que los partidos democráticos de izquierda no han logrado convertirse en alternativas coherentes de gobierno (con las excepciones de Brasil y Chile), los descontentos sociales ante la democracia y las protestas políticas contra los gobiernos en turno no han cesado. De hecho, el resultado de este desencanto ha sido canalizado como nunca antes en la historia de América Latina de forma eficaz, al traducirse las protestas en juicios políticos o posmodernos impeachments tropicales y renuncias sonadas de primeros mandatarios con muy novedosos exilios, extraños asilos y espectaculares huidas. En total, en los años 90 y hasta el 2001 tenemos a no menos de siete presidentes de República ${ }^{1}$ que han tenido que abandonar sus cargos por distintas presiones políticas que provenían principalmente de una pérdida de legitimidad interna, de una crisis política prolongada y azuzada también desde la calle a través de un continuum de manifestaciones y protestas pacíficas o violentas. ${ }^{2}$

El problema planteado por estas nuevas formas de expresión política reside en que detrás de dichas dinámicas de cambio político y de crítica al poder establecido, a los programas económicos

${ }^{1}$ Collor de Mello en Brasil, Carlos Andrés Pérez en Venezuela, Jorge Serrano en Guatemala, Abdalá Bucaram y Jamil Mahuad en Ecuador, Alberto Fujimori en Perú y Fernando de la Rúa en Argentina. Muy cerca han estado, y están todavía, Hugo Chávez de Venezuela y Gonzalo Sánchez de Losada de Bolivia.

${ }^{2}$ En su edición del domingo 16 de marzo de 2003, la revista de El País Semanal, de España, mostraba un titular que anunciaba el tono de la época: Rebelión en la calle, con el subtítulo: "Todo empezó en Porto Alegre. La sociedad mundial se organiza y toma las ciudades". 
en marcha o a los estilos de gobierno, no sólo encontramos una voluntad democratizadora y popular sino un riesgo latente de retroceso autoritario y recuperación elitista al más puro estilo de la tradición política latinoamericana que subraya el divorcio entre el mítico país real y el país legal.

Para tratar de acercarnos a estos nuevos fenómenos políticos que plantea la siempre conflictiva relación entre sociedad civil y Estado en nuestro continente procederemos en dos partes. Primero, interpretando la multiplicación de estas crisis políticas como expresión latinoamericana de la sociedad del riesgo; segundo, señalando que el vacío dejado por estas situaciones de crisis es ocupado, a través de la sociedad civil, más por las élites que por los pueblos en su voluntad de cambio. Esto último explicaría la dificultad para crear alternativas de gobierno a la hegemonía política y económica de la globalización en América Latina, así como a las profundas dudas y limitaciones inherentes a la acción democratizadora de la sociedad civil.

\section{Del riesgo a la crisis}

"La sociedad del riesgo" es el sugerente título del libro más conocido del sociólogo alemán Ulrich Beck (1998). Su propuesta teórica nos puede ser útil para comprender el tipo de crisis política, no revolucionaria, que han tenido que enfrentar gobiernos y actores políticos latinoamericanos en la última década. Y sin duda nos permitirá también comprender que la multiplicación de las crisis nos coloca ante la presencia de novedosos vacíos políticos.

Muy someramente, para Beck (1998), la sociedad del riesgo es la configuración de nuevos problemas sociales, científicos y políticos surgidos de la lógica misma de la modernidad, peligrosamente amplificada y fragmentada por el proceso de globalización. Los riesgos afectan a los mismos centros de producción y a los propios actores-conductores de la modernidad, generando así un peligroso efecto boomerang porque su causalidad no tiene límites, multiplicando los efectos perversos. Ante esto se reconfiguran las tradicionales nociones de clase, ciudadanía, espacio público y control, y queda al descubierto la imposibilidad del control absoluto. La sociedad del riesgo de Beck es una sociedad de múltiples y recurrentes crisis. Su paradoja es que en la sociedad del control, el descontrol es el rasgo principal. La multiplicación de las crisis derivadas de los riesgos inherentes a la producción material y simbólica de objetos y sentidos genera también una 
inusual movilización multisectorial de resistencia que a veces puede aparecer como fragmentada e inconexa, pero que en otras es capaz de centralizar y focalizar su acción con eficiencia. Sin embargo, ni siquiera cuando lo logra se puede comparar a una movilización de tipo revolucionaria (entendida ésta como omniabarcante en el tiempo y el espacio), ya que su éxito está basado en el mismo mecanismo que la produjo: la extensión de la propia lógica moderna de la sociedad del riesgo.

La expresión inédita de estos fenómenos en América latina, traídos consigo por la democratización, la globalización, el neoliberalismo y el neopopulismo se han vivido en directo, y hasta con recurrencia, en el caso de las crisis políticas que terminaron con la salida y renuncia de varios presidentes.

No hay acción ciudadana sin víctima política. Los tambores rituales anuncian siempre algo más que la aplicación de la ley: el sacrificio de uno en nombre de todos. En América Latina, los progresos incontestables de la democracia y de la opinión pública han traído consigo excesos y ajustes de cuentas entre las élites políticas. Disfrazados de legalidad y justicia, amparados por el clamor popular e invadidos por una sed de racionalidad y transparencia, los actores políticos más tradicionales del continente han sabido sacar provecho de la apertura democrática. En nombre de las instituciones se han violentado a las propias instituciones.

Los acontecimientos del 2000 en Ecuador, en donde el presidente Mahuad fue derrocado tras una serie de confusas manifestaciones con participación de los grupos indígenas de la CONAIE (Confederación de Nacionalidades Indígenas del Ecuador) y de facciones militares, que determinaron el ascenso al poder del vicepresidente Noboa. Desde Brasil a Guatemala, pasando por Venezuela y el Perú, actores políticos de primer nivel se han visto acusados de todos los delitos, obligados a partir al exilio o a vivir en ostracismo. En algunos casos se trató del mismísimo Presidente, quien llegaba al poder envuelto en la aureola del héroe. En otros se trataba de líderes políticos de gran factura, partícipes de los avances democráticos. Pero siempre de personajes centrales en la vida política de un país. Podemos preguntarnos, entonces, si acaso estas caídas no corresponden más bien a un cambio en los pactos entre las élites en los sistemas políticos que a una verdadera toma de conciencia ciudadana.

A fines de 1992, Fernando Collor de Mello, Presidente electo de Brasil, era destituido a través de un impeachment por la Asamblea y el Senado. Después de multitudinarias manifestaciones en 
las principales ciudades de Brasil que hacían eco al descubrimiento de una red de influencias que involucraba a familiares y ministros, el presidente tenía que retirarse y enfrentar cargos de corrupción. En Venezuela, en mayo de 1993, Carlos Andrés Pérez era destituido también acusado de corrupción. Y en junio del mismo año, en Guatemala, Jorge Serrano era derrocado por intentar cerrar el parlamento al estilo Fujimori. Más cerca, en 1997, en Ecuador, el presidente Bucaram era derrocado en condiciones similares a las de Mahuad, pero esta vez escapando del país, evitando así un proceso en su contra. Por último, en el 2001 Fujimori y De la Rúa, presidentes de Perú y Argentina, tuvieron que renunciar a sus respectivos cargos de forma poco decorosa, tras la presión conjunta de la calle y el parlamento.

Es allí que la 'ley de la calle' como expresión negativa aparece en el corazón del conflicto político. Consiste en saber hasta qué punto un sistema político escucha a la gente o hasta qué punto escamotea su voluntad confiscándole su soberanía y alejando a la sociedad de las decisiones que la afectan. Esta expresión nos remite también al temor, al reino del más fuerte, a la ausencia de reglas pacíficas para sortear los conflictos. Pero también reúne, tras una metáfora, a los movimientos sociales y a la sociedad civil en su dinámica: una dinámica basada en la acción ciudadana, vigorosa y libre, que privilegia la expresión directa por encima de la representación política que mediatiza y atempera. Viene a colocar en el centro del debate el lugar de los excluidos, de la plebe no representada, expropiada de su libertad. Pero, además, parece contener el fantasma del populismo en su versión latinoamericana, capaz de capitalizar políticamente el descontento y la protesta, remitiéndonos finalmente a las virtudes de la sociedad frente a las perversiones del Estado.

Estas posmodernas crisis políticas en el contexto de la sociedad del riesgo parecen surgir tanto de la tradicional debilidad del Estado como de la capacidad re-legitimizadora de los actores de la sociedad civil. Como nos lo recuerdan Anthony Pagden y Luis Castro Leiva, en América Latina la construcción estatal del siglo XIX tenía como objetivo crear una sociedad civil que fuera capaz de asegurar la felicidad para sus miembros. Después de la revolución rusa, señalan los autores, el objetivo se invirtió paso a paso, acelerándose, paradójicamente, durante los 90; para la sociedad se trata de 'eliminar', lo más posible, al Estado (Castro y Pagden, 2001). 
Si hay crisis es porque ésta se debe en primer lugar a la imposibilidad que tiene el Estado, no sólo de oír las criticas que le llegan desde la calle, sino que en su misma estructura o aparatos no existen mecanismos, ni políticos ni burocráticos, para corregir rumbos y afinar estrategias con el fin de responder a las demandas.

Así, nos parece sugerente la postura de O’Donnell (1988) al sugerir la necesidad de fortalecer las instituciones del Estado que promuevan una accountability horizontal. Definida esta última como la "existencia de agencias estatales que tienen la autoridad legal y están fácticamente dispuestas y capacitadas para emprender acciones, que van desde el control rutinario hasta las sanciones legales o incluso impeachment, en relación con actos u omisiones de otros agentes o agencias del Estado que pueden, en principio o presuntamente, ser calificadas como ilícitos" (O’Donell, 1988: 173-174). Por lo tanto, la ausencia de estos mecanismos o virtudes del sistema político, más allá de la acción ciudadana, puede acelerar o agudizar las situaciones de descomposición de un gobierno o de un régimen.

Pero, ¿si las instituciones fallan? La crisis se ahonda y es recuperada por la calle. Bobbio nos recuerda que, en la tradición, la última instancia de legitimidad en una crisis política de gobernabilidad es la sociedad civil. El italiano plantea la relación entre gobernabilidad y sociedad civil como un eje que es articulado por el problema de la legitimidad. Así "la sociedad civil es sede donde se forman, especialmente en los periodos de crisis institucional, los poderes que tienden a obtener su legitimidad incluso en detrimento de los poderes legítimos, donde, en otras palabras se desarrollan los procesos de deslegitimación y relegitimación". Y añade, "de aquí que la frecuente afirmación de que la solución de una crisis grave que amenaza la sobrevivencia de un sistema político debe buscarse ante todo en la sociedad civil, donde se pueden encontrar nuevas fuentes de legitimización, y por tanto nuevos espacios de consenso" (Bobbio, 1989). El comentario de Bobbio nos permite sopesar los elementos del conflicto a partir de las demandas, presiones y acciones de la Sociedad Civil, sin la cual no podemos imaginar ningún escenario de gobernabilidad, porque revela que en el corazón del cambio está esa legitimidad en disputa por parte de múltiples actores políticos. Sin embargo, un análisis poco cuidadoso podría llevarnos a creer que la única legitimidad posible está, 'material y espiritualmente', en la sociedad civil. Esta tentación podría entonces conducirnos a pensar en una subjetividad radical de la sociedad civil opuesta a cualquier 
forma racional e institucional de regulación de conflictos, volviendo a oponer la supuesta pureza del país real a la supuesta corrupción del país legal.

\section{De la crisis a la elitización}

La sociedad del riesgo conjuga la noción de crisis bajo el signo de lo múltiple y lo continuo. La recurrencia de los procesos de crisis política sin solución refuerza, por un lado, la inestabilidad de los frágiles regímenes democráticos, y por otro la fragmentación de las luchas políticas que dan pie a esas crisis. Nunca antes de los años 90, en la historia de América Latina, tantos presidentes habían sido derrocados o se habían visto obligados a renunciar al poder por la amenaza de juicios políticos o la realización de manifestaciones en su contra. Históricamente, la inestabilidad política provenía de los golpes de Estado, pero durante los años noventa no había que temerle ni a los militares, ni a las elecciones, sino a la presión de las manifestaciones y a las constantes movilizaciones de la sociedad civil.

Pocas veces en América latina, el axioma de Claude Lefort de que la democracia es un espacio vacío, lugar de la incertidumbre y de la ausencia de trascendencia de las normas ha sido más cierto que durante los años 90. Para Lefort, autor de La invención democrática: "la democracia asocia dos principios aparentemente contradictorios: uno, que el poder emana del pueblo; el otro, que ese poder no es de nadie". Y agrega que, la democracia, "sin embargo, vive de esta contradicción” (Lefort, 1981). Pero Lefort va más allá al sugerir que es el Estado, en última instancia, el que dota de una dimensión simbólica que permite darle forma y cohesión a la sociedad civil, convirtiéndola en la expresión secular del tradicional cuerpo del rey teológico-político.

Lo que nos interesa señalar aquí es que con la multiplicación de las crisis de gobernabilidad en América Latina, quedaba al descubierto la desnudez del poder que debía representar la voluntad del pueblo y se convertía -no sólo simbólicamente- en un espacio realmente vacío, abandonado incluso durante las pugnas entre los distintos grupos de la sociedad civil, a merced de las negociaciones a espaldas de los ciudadanos en los casos de los nombramientos de los sustitutos de los presidentes salientes o de los interminables cabildeos parlamentarios con resultados más que confusos. Fue el caso en el Perú y en Argentina (este último con una enigmática danza de cinco presidentes al hilo), pero también 
en Ecuador en las dos ocasiones de crisis presidencial. Incluso, en el caso venezolano de abril de 2002, fue la oportunidad para que el depuesto Hugo Chávez recuperara el poder.

Así que la democracia mostraba su rostro no sólo como territorio de conflicto entre el conjunto de la pluralidad y diferencia de la sociedad civil, sino sobre todo como espacio vacío, ya no en el sentido figurado, sino literalmente hablando. Los países latinoamericanos envueltos en estas crisis vivieron horas de ausencia real en los controles materiales del gobierno y el Estado. Pocas veces como entonces el vacío político se hacía tan patente en la experiencia histórica de nuestras sociedades.

Pero sin duda este vacío, esta ausencia en los espacios materiales desde donde se ejerce ritualmente el poder de los gobiernos, esta dispersión de opciones contradictorias, este magma social expresado con fuerza irrefrenable a través de la movilización social en las calles dejaba la puerta abierta a una nueva, pero extraña recomposición. Después de la perplejidad ante el vacío, después de darse cuenta de que, en efecto, la protesta caótica había ganado, se generaba un extraño sentimiento de desorientación al desaparecer el personaje que encarnaba al 'enemigo'.

He allí que una nueva hegemonía se reconstruía al amparo y gracias al vacío generado por la movilización de la sociedad civil en las calles. Al multiplicar las demandas muchas veces inconexas y altamente diferenciadas de esa muy plural sociedad civil, o al contrario, su carencia de demandas específicas y la expresión de bronca, frustración o reivindicación de una ética ante la maquiavélica lógica del poder, lo que se producía era una emergencia de significantes vacíos. Como lo explica Ernesto Laclau (2000), vacíos en tanto significantes de la categoría de falta, de una totalidad ausente, indisponible dirían los psicoanalistas. Ahora bien, ¿cuál de las opciones políticas en juego podía, en los contextos particulares de las movilizaciones, reunificar, articular, sumar a los actores para eventualmente convertirlos en sujeto y definir una hegemonía? La respuesta es ninguna... Más que el carácter desigual de lo social que se reinstala en la historia presente a través de la figura de las élites.

La relación por la cual un contenido particular se convierte en el significante de una plenitud comunitaria ausente es lo que se define como una relación hegemónica [...] una clase o un grupo son considerados como hegemónicos si no se quedan encerrados en una perspectiva estrechamente corporatista, y más bien se presentan como realizando, 
para sectores más amplios de la población, objetivos más vastos como son los del orden o la emacipación. (Laclau, 2000: 102-103). ${ }^{3}$

Observamos entonces que lo que unificaba a los muy diversos sectores movilizados por la sociedad civil a la hora de expresar su descontento y repudio era la figura misma del personaje político en cuestión. Al dejar vacío el poder, este 'enemigo' dejaba al descubierto de forma indirecta la multitud de significantes vacíos desarticulados entre sí, sin mediador interno, sin un liderazgo específico claro que pudiera dar forma a la nueva relación hegemónica por construirse.

El poder dejado vacante era ocupado por novedosas élites sociales y económicas, únicas capaces de hacer jugar a su favor la desigualdad social y la fragmentación a ultranza del descontento social. La tesis no es nueva, lo interesante es que, anteriormente, en las discusiones sobre movimientos sociales, los que sacaban provecho de las turbulencias políticas eran los miembros de un sector de profesionales o emprendedores políticos altamente especializados. Ahora, esos tradicionales actores de un modelo lenninista son apenas actores secundarios y los actores principales son las élites dotadas de un capital simbólico y cultural, económico y político que hace la diferencia.

En ese caso ya no hablamos ni de los tradicionales activistas profesionales ultrapolitizados, ni de las oligarquías tradicionales de mediados del siglo xx, sino de un reducido grupo de actores interesados por el poder político dejado vacío, dotados de un fuerte capital simbólico. Más solitarios que orgánicos, síntesis del nuevo outsider y del viejo condottiere, son capaces, al mismo tiempo, de burocratizar al movimiento social y de recomponerlo con nuevos discursos. En todos está latente una soledad laberíntica que los coloca, a pesar suyo, como jefes de movimientos sin tropa. Provenientes de muy diversos horizontes sociales y depositarios de la formación escolar otorgada por los procesos de modernización de las sociedades latinoamericanas de los años 50 y 60, las élites son tan diversas como la misma sociedad que los ha parido (citado en Lipset y Solari, 1967). Estas élites son indígenas en su actual acepción indianista, como Nina Pakari, fugaz ministra de relaciones exteriores en Ecuador o Evo Morales, líder de la oposición en Bolivia; guerrilleros como el Sub-Marcos en México o Tirofijo en Colombia; sindicales como Carlos Ortega en Venezuela o José Luis Risco en Perú, empresarios como Pedro Car-

\footnotetext{
${ }^{3}$ La traducción es del autor de este artículo.
} 
mona en Venezuela o Lino Korrodi en México, intelectuales como Cardoso en Brasil o Castañeda en México, deportistas como Reutemann en la Argentina, militares como Lucio Gutiérrez en Ecuador y hasta políticos disímiles como Alejandro Toledo en Perú o Eduardo Duhalde en Argentina. ${ }^{4}$

Su característica principal es la de romper con las imágenes del pasado, del tradicional discurso hegémonico y populista y de intentar refundar el presente solamente desde una acción política decidida consciente de que su liderazgo es minoritario y está seriamente acotado, pero con la flexibilidad negociadora capaz de lograr consensos mínimos, tanto en sus propios espacios organizativos como hacia fuera, con el resto de la sociedad. Pocas veces como antes estas élites han gozado de la oscilación mediática, efímera pero siempre impactante. Atrás quedaban los índices de aprobación plebiscitaria de nuestros viejos caciques populistas capaces de generar amplios consensos nacionales, es decir procesos hegemónicos tan duraderos como el mismo proyecto del Estado-Nación. Estas élites no son más mercuriales y cambiantes que las anteriores, pero sí son estrellas más fugaces, personajes más flexibles, menos heroicos y más humanos, pero sobre todo muy frágiles en el tiempo: viven del vaivén del rating, elegidos de un día, nominados de siempre, como héroes deportivos pasajeros; más que ídolos con pies de barro, íconos de alguna extraña academia política sin claustro, sobrevivientes de alguna operación triunfo. Estas élites se nutren de la confusión de nuestra época y terminan expresándola mejor. Su nostalgia está en el futuro, ya que el presente los envejece prematuramente y el pasado realmente nunca les perteneció.

Estas élites son las que juegan un papel de mediadores fundamentales al momento de recomponer los vacíos dejados por la protesta y la crisis ante el gobierno saliente. Adaptan sus discursos desde la sociedad hacia el Estado para legitimar su novedosa presencia y ensanchar así los márgenes de gobernabilidad. Justamente porque este concepto involucra dimensiones de legitimidad y eficiencia que ya no parten del propio corazón del gobierno, es que nos parece fundamental hacer una reflexión que vincule las nociones de gobernabilidad con la de gubernamentalidad.

Aunque parezca extraño, este concepto acuñado por Michel Foucault (1991) se refiere a la cada vez mayor autonomía del

\footnotetext{
${ }^{4}$ Habrá que agregar el historiador y periodista de televisión Carlos Mesa, presidente de Bolivia.
} 
gobierno de los hombres y las cosas en relación con el Estado. Después de señalar que lo más importante para la modernidad no es la estatización de la sociedad sino la gubernamentalización del Estado, Foucault define:

La gubernamentalización del Estado es un fenómeno singularmente paradójico, ya que si bien los problemas de la gubernamentalidad, las técnicas de gobierno han constituido la única apuesta del juego político y el único espacio real de la lucha política; la gubernamentalización del Estado ha sido sin duda el fenómeno que le ha permitido sobrevivir, y muy probablemente el Estado es actualmente lo que es gracias a esa gubernamentalidad, que es a la vez interna y externa al Estado, ya que son las tácticas de gobierno las que permiten definir paso a paso qué es lo que le compete y qué es lo que no le compete, qué es lo público y qué es lo privado, qué es lo estatal y qué es lo no estatal, etc. (Foucault, 1991: 25-26).

Antes de llegar hasta allí, Foucault señalaba tres puntos importantes: 1) La pluralidad sincronizada de las formas de gobierno respecto del Estado y la inmanencia de esta actividad como conexas y entrelazadas en el interior de la sociedad; 2) El arte de gobierno y el poder del príncipe no son discontinuos con relación a otras formas de poder como la economía y la moral; 3) El contrato viene a ser la matriz teórica a partir de la cual se intentan alcanzar los principios generales de un arte de gobierno. Estos tres puntos sostienen en su acepción política a la gubernamentalidad, desde por lo menos el siglo XVIII (Foucault, 1991: 13).

Foucault (1991) nos recuerda que debemos pensar la gubernamentalidad como algo más complejo, desligado del aparato de Estado, que ocurre también en el ámbito de lo social, a través de las élites y que, a su vez, está habitado por la racionalidad de los equilibrios, técnicas y tácticas de lo gubernamental en su educación política. Esta perspectiva nos lleva a entender mejor que los márgenes de control político entre las diferentes esferas están mucho más cerca el uno del otro que lo que en algunos casos se cree.

En otras palabras, lo que queremos sugerir es la posibilidad de que a través de la gubernamentalidad, es decir, de la presencia continua de la sociedad en las decisiones políticas más allá de la lógica coactiva del Estado, se hayan dado formas de representatividad eficientes pero que desbordan el marco institucional y las reglas básicas del juego democrático y donde es fundamental el papel de las élites como mediadoras y transformadoras. 


\section{Conclusión}

Para salir de la crisis las recetas son siempre riesgosas, pero hay que saber tomar los riesgos necesarios. Si la accountability horizontal puede ser un elemento fundamental para darle equilibrio al sistema político en sus futuras crisis, no podemos olvidar que la sociedad civil puede reclamar la redefinición de la legitimidad en los momentos de mayores problemas políticos. Esta noción nos conduce, entonces, a asumir que los problemas de gobierno no están sólo en aquellos que gobiernan, sino en la relación de éstos con el resto del cuerpo social. Esta continuidad de los eslabones del poder nos plantea la urgencia de profundizar la noción de gubernamentalidad que sería uno de los aportes de la modernidad, trascendiendo la dicotomía Estado y sociedad y dejando aparecer a unas novedosas élites. El riesgo es que, al pensar de este modo, nos encontramos con una larga tradición de fortaleza de la sociedad civil, entendida como reino de los particularismos. Esta dinámica histórica muy particular refleja una tentación constante en reclamar acciones políticas directas que faciliten la expresión en el corto plazo basándose en negociaciones poco transparentes. Esta situación desbordaría de hecho, no sólo el marco legal, sino el esquema institucional de la representación en favor de la expresión directa de la voz de unos y otros, pero bajo la amenaza del más fuerte, al estilo de la ley de la calle. Esto produce una apuesta en términos estratégicos de la violencia simbólica o de la amenaza que fragiliza a la larga el sistema democrático en un periodo de cambio y reacomodo político.

El reto, y el riesgo, es dejarse llevar por una fragmentación a ultranza que reafirme el poder de las élites como únicos actores dirigentes de la sociedad civil en este nuevo contexto. Con su mayor capacidad de negociación por sus vínculos económicos y sociales con los gobiernos, las élites podrían ser las depositarias momentáneas de las iniciativas de la sociedad civil o las monopolizadoras del discurso democrático implícito en su dinámica. Saltando incluso por encima de los partidos, asociaciones y organizaciones no gubernamentales pertrechadas por sus asociaciones mínimas y con fuertes tendencias corporativas, las élites podrían poner en riesgo parte de los valores democráticos implícitos en la esfera de la sociedad civil. Este detalle es relevante cuando observamos que la nueva legitimidad surgida de las protestas es la de los sectores conservadores como en Venezuela. Pero también cuando recordamos las tradiciones de ciertos grupos de la izquierda 
en el continente, más proclives a crear su propia asociación (de cofradías tipo entre-nous) que a buscar una acción abierta en el espacio público, enriqueciendo el debate democrático. Por eso, los sectores populares, también muy fragmentados en su identidad, acción y representación, podrían verse aislados y abandonados a la suerte violenta que les depara la calle a los más humildes de América Latina. Excluídos de la política por el abstencionismo electoral o por su dependencia clientelar, pero también a espaldas de la sorprendente sociedad civil.

\section{Bibliografía}

Beck, Ulrich (1998), La sociedad del riesgo. Hacia una nueva modernidad, Paidós, Barcelona.

Bobbio, Norberto (1989), Estado, gobierno y sociedad, Por una teoría general de la política, México, FCE.

Castro Leiva, Luis y Anthony Pagden (2001) "Civil society and the fate of modern republics of Latin America”, en Sudipata Kaviraj y Sunil Khilnani (eds.), Civil Society, History and Possibilities, Cambridge University Press, Cambridge.

Foucault, Michel (1991), "La gubernamentalidad”, en Espacios de poder, Genealogía del poder núm. 6, Ed. de la Piqueta, Madrid.

Laclau, Ernesto (2000), La guerre des identités. Grammaire de l'émancipation, La Découverte, Paris.

Lefort, Claude (1981), L'invention démocratique, Paris, Fayard.

Lipset Seymour, Martin y Aldo Solari (1967), Elites in Latin America, Oxford University Press, New York.

O’Donnell, Guillermo (1988), “Accountability horizontal” en La Política, núm. 4, 1988, octubre, pp. 173-174. 
El País Semanal (2003), "Rebelión en la calle: todo empezó en Porto Alegre, la sociedad mundial se organiza y toma las ciudades”, 16 de marzo 2003, España.

Enviado: 17 de noviembre de 2003. Aprobado para su publicación: 16 de febrero de 2004. 